International Journal of Current Advanced Research

ISSN: O: 2319-6475, ISSN: P: 2319 - 6505, Impact Factor: SJIF: 5.995

Available Online at www.journalijcar.org

Volume 6; Issue 3; March 2017; Page No. 2836-2839

DOI: http://dx.doi.org/10.24327/ijcar.2017.2839.0120

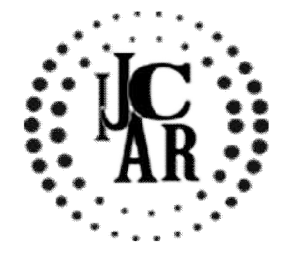

Research Article

\title{
SOME STUDIES ON INVESTIGATING THE CONCEPT OF DETERMINING THERMAL CONDUCTIVITY OF VARIOUS INSULATING POWDERS MATERIALS BY USING SPHERE IN SPHERE METHOD
}

\section{Shubham Sharma ${ }^{1}$ and Shalab Sharma ${ }^{2}$}

${ }^{1}$ Mechanical Engineering D.A.V University Jalandhar Punjab, India

${ }^{2}$ Mechanical Engineering CT Institute of Technology, Jalandhar Punjab, India

\section{A R T I C L E I N F O}

\section{Article History:}

Received $20^{\text {th }}$ December, 2016

Received in revised form $24^{\text {th }}$ January, 2017

Accepted $4^{\text {th }}$ February, 2017

Published online $28^{\text {th }}$ March, 2017

\section{Key words:}

Thermal conductivity, Plastic of Paris, Marvel sand, Rock sand, Brick sand

\begin{abstract}
A B S T R A C T
Insulating materials are the most powerful tool for design and construction to achieve high energy conservation in building, automobile sector, thermal power plant etc. Recognizing the need and efficient use of heat energy and its conservation in every sector. This paper is tried to find out the thermal conductivity of insulating powder with varying temperature. Study shows that the thermal conductivity of pop powder, rock sand, and brick sand powder is increasing with the increase in temperature, on the other side the thermal conductivity of marvel sand is decreasing with the increase in temperature. Practical investigation show that the thermal conductivity of pop powder is suitable for $0{ }^{\circ} \mathrm{C}$ to 100 ${ }^{0} \mathrm{C}$ temperature, thermal conductivity is $0.221 \mathrm{~W} / \mathrm{mk}$ to $0.439 \mathrm{~W} / \mathrm{mk}$ within this temperature range, which is very much less as compared to other selected insulator materials. In the next highest temperature range $100^{\circ} \mathrm{c}$ to $120^{\circ} \mathrm{c}$ the mixture powder (POP + Brick sand) thermal conductivity is $(0.41 \mathrm{~W} / \mathrm{mk}$ to $0.48 \mathrm{~W} / \mathrm{mk})$, in this temperature range this mixture powder give us a effective result of low thermal conductivity instead of other selected insulator materials. In Indian market cost of pop powder and brick sand is Rs.14 and Rs.8 per kg respectively so according to our working condition we can choose a more suitable insulator material.
\end{abstract}

Copyright $₫ 2017$ Shubham Sharma and Shalab Sharma. This is an open access article distributed under the Creative Commons Attribution License, which permits unrestricted use, distribution, and reproduction in any medium, provided the original work is properly cited.

\section{INTRODUCTION}

The transmission of energy from one location to another location is called as heat transfer. Conduction is the transfer of heat or energy which occurs due to the collisions of particles or molecules within a body. In any heating process, the heat will flow outwards from its generation point. while it flow outwards its mean that there are lot of loses of heat, so to reduce these types of loses as much as, we use different kinds of insulations materials. The insulations may be in various form such as paints, powders etc. In this paper we used different types of powders materials, for example pop, brick sand, marvel sand, rock sand. We also calculated the thermal conductivity of these various insulating powders to find out the reasonable thickness of insulation. Thermal conductivity means that the rate at which heat passes through a materials. A low thermal conductivity powder is good to reduce the heat losses during the heating process. So here we calculated the thermal conductivity of powders at various temperatures for further understanding.

\section{LITERATURE REVIEW}

Thermal insulators are those materials which shut the flow of heat energy.

*Corresponding author: Shubham Sharma

Mechanical Engineering D.A.V University Jalandhar

Punjab, India
Calcium silicate is one of the best light weight thermal insulators materials for high temperature [1]. It cover the temperature range from $40^{\circ} \mathrm{C}$ to $95^{\circ} \mathrm{C}$ in which the materials is not deformed its shape. It is water absorbent and due to its high strength it is used on hot piping and surface. It's thermal conductivity is about $0.0462 \mathrm{~W} /(\mathrm{mk})$ at room temperature [1]. Brick sand is also a good insulation powder it has a good insulation properties. A brick sand powder has high porosity range due to which it contained more air and the result is that the thermal conductivity is fall down. In bricks to raise the porosity some additive are added into mixture

Brick sand is also a good insulation powder it has a good insulation properties. A brick sand powder has high porosity range due to which it contained more air and the result is that the thermal conductivity is fall down. In bricks to raise the porosity some additive are added into mixture before firing [2]. It's thermal conductivity range $0.15 \mathrm{~W} /(\mathrm{mk})$ at temperature range $215^{\circ} \mathrm{C}$ to $250^{\circ} \mathrm{C}$.

Fibre glass has hold very fine fibre of glasses. It is used in pipe insulation application, by trapping air within blocks of glass fibre makes good thermal insulation. The random path is the main factor on which the thermal conductivity of fibre glass is depends [3]. The temperature range of fibre glass insulation is $-30^{\circ} \mathrm{C}$ to $540^{\circ} \mathrm{C}$. The thermal conductivity of fibre glass is $0.04 \mathrm{~W} /(\mathrm{mk})$. 
Porous silica is one of very good insulative material. It has very low thermal conductivity due to its high porosity in which solid heat conduction is very low [4]. Further to reduce more thermal conductivity of silica powder we can add some substance, for exampleTiO2, Fe3O4 and carbon black [5].

\section{Experimental Set $U p$}

Experimental set up to measure thermal conductivity is shown in figure 1. In this set up we use 'sphere in sphere' method to calculate the thermal conductivity of insulating powders.

This apparatus consist of two spherical shells and insulating material (in powder form) whose conductivity is to be calculated is packed between these two shells. A heating coil is attached to the inner shell. The power is supplied from outside through auto-transformer for heating purpose. The power supply of heater is controlled by a dimmerstat and is measured on voltmeter and ammeter. Thermocouples are attached along the radius of inner and outer sphere to measure the temperature. Four thermocouples are attached on the outer surface of inner sphere and six thermocouples are on the inner surface of outer sphere, these all thermocouples are further attached to a multichannel digital indicator. From average of outer and inner sphere temperature we can calculate the temperature difference across the layer of powder.

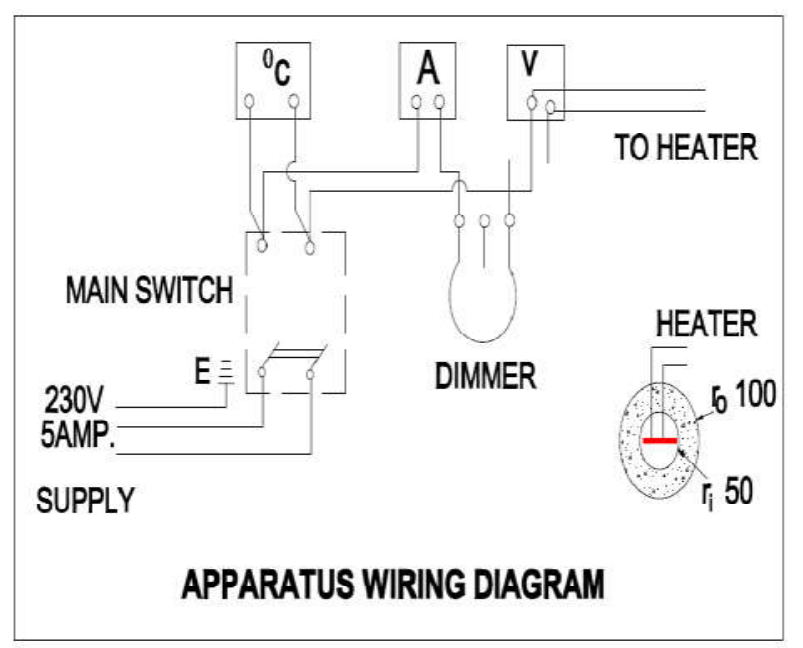

Fig 1 Apparatus wiring diagram

Here $r_{i}=50 \mathrm{~mm}$ and $r_{0}=100 \mathrm{~mm}$ both are the radius of inner sphere and outer sphere respectively. A mica flat heater is used for heating purpose which is fitted inside the inner sphere. Dimmerstat (0-230 volts, 2A capacity) works as a controller, and voltmeter (0-200 volts) and ammeter (0-1 amp) both are measureable devices. A multichannel digital temperature indicator is used for measuring the temperature.

By applying the Fourier's law of heat conduction for spherical layer of radius ' $r$ ' and thickness (ro-ri) with temperature difference (ti-to) the heat transfer rate.

$\mathrm{q}=\frac{4 \pi k \operatorname{riro}(\mathrm{Ti}-\mathrm{To})}{(\text { ro }-\mathrm{ri})}$

Where $\mathrm{k}$ is thermal conductivity, it determine as

$\mathrm{K}=\quad q(r o-r i) \quad$ at $(\mathrm{Ti}+\mathrm{To}) / 2 \quad{ }^{0} \mathrm{C}$

$4 \pi \operatorname{riro}(T i-T o)$

Heater input $-\mathrm{q}=\mathrm{V}$ x I Watts

$$
\mathrm{Ti}=\frac{\mathrm{T} 1+\mathrm{T} 2+\mathrm{T} 3+\mathrm{T} 4}{4}{ }^{0} \mathrm{C}
$$

Average outer sphere surface temperature

$$
\mathrm{To}=\text { - }
$$

\section{RESULT AND DISCUSSION}

Experimental research about thermal insulating powder materials performance shows some meaningful changes under varying temperature. On the basis of this study we can decide the appropriate insulating powder materials for different industrial and building applications.

Table 1 Thermal Conductivity of Plaster of Paris (pop) powder

\begin{tabular}{ccccccc}
\hline S.No. & I & V & Ti & To & K & TM \\
\hline 1 & 0.3 & 80 & 106.75 & 20.06 & 0.221 & 63 \\
2 & 0.33 & 100 & 135.5 & 25.08 & 0.238 & 80 \\
3 & 0.4 & 120 & 157.5 & 28.05 & 0.295 & 93 \\
4 & 0.45 & 140 & 167.75 & 32.33 & 0.37 & 100 \\
5 & 0.5 & 150 & 171.75 & 35.67 & 0.439 & 104 \\
\hline
\end{tabular}

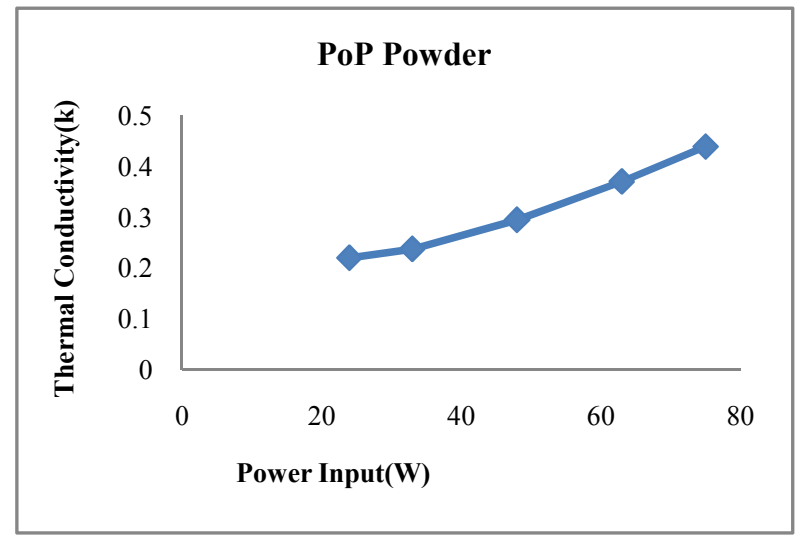

Fig. 2 Variation of Thermal conductivity of Plaster of Paris Powder (pop) with power input.

Fig. 2 shows the variation of thermal conductivity with the variation of $\mathrm{q}$ as we increase the temperature there is rise in thermal conductivity, but it's a linear change of thermal conductivity. It is suitable for $0{ }^{0} \mathrm{C}$ to $100{ }^{0} \mathrm{C}$ temperature, its thermal conductivity is varied from $0.221 \mathrm{~W} / \mathrm{mk}$ to 0.439 $\mathrm{W} / \mathrm{mk}$ within this selected temperature range.

Table 2 Thermal conductivity of Marvel Sand powder

\begin{tabular}{ccccccc}
\hline S.No. & $\mathbf{I}$ & $\mathbf{V}$ & $\mathbf{T i}$ & $\mathbf{T o}$ & $\mathbf{K}$ & $\mathbf{T M}$ \\
\hline 1 & 0.3 & 80 & 55.5 & 25.33 & 0.63 & 40 \\
2 & 0.33 & 100 & 67.5 & 28.5 & 0.67 & 48 \\
3 & 0.4 & 120 & 93.5 & 32.5 & 0.63 & 63 \\
4 & 0.45 & 140 & 117.75 & 34.6 & 0.6 & 76 \\
5 & 0.5 & 150 & 147.5 & 32.8 & 0.52 & 90 \\
\hline
\end{tabular}

Fig. 3 shows that the thermal conductivity of Marvel sand insulating powder is linearly varied with the variation of $q$ but with the continuous rise of $\mathrm{q}$ the thermal conductivity of marvel sand is going to downwards. This graph show that thermal conductivity of marvel sand is decreased from 0.63 to 0.5 , so that this materials is used for high temperature in industries and building materials.

Average inner sphere surface temperature 


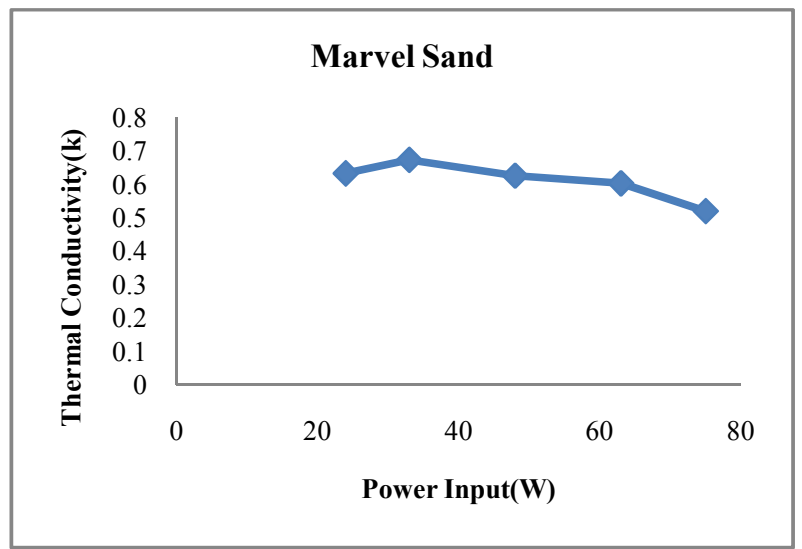

Fig. 3 Variation of Thermal conductivity of Marvel Sand powder with power input.

Table 3 Thermal Conductivity of Rock Sand powder

\begin{tabular}{ccccccc}
\hline S.No. & I & $\mathbf{V}$ & Ti & To & K & TM \\
\hline 1 & 0.3 & 80 & 84.75 & 37.16 & 0.4 & 61 \\
2 & 0.33 & 100 & 91 & 38.41 & 0.5 & 65 \\
3 & 0.4 & 120 & 130.75 & 43 & 0.44 & 87 \\
4 & 0.45 & 140 & 149.5 & 45.93 & 0.48 & 98 \\
5 & 0.5 & 150 & 165.25 & 57.58 & 0.55 & 111 \\
\hline
\end{tabular}

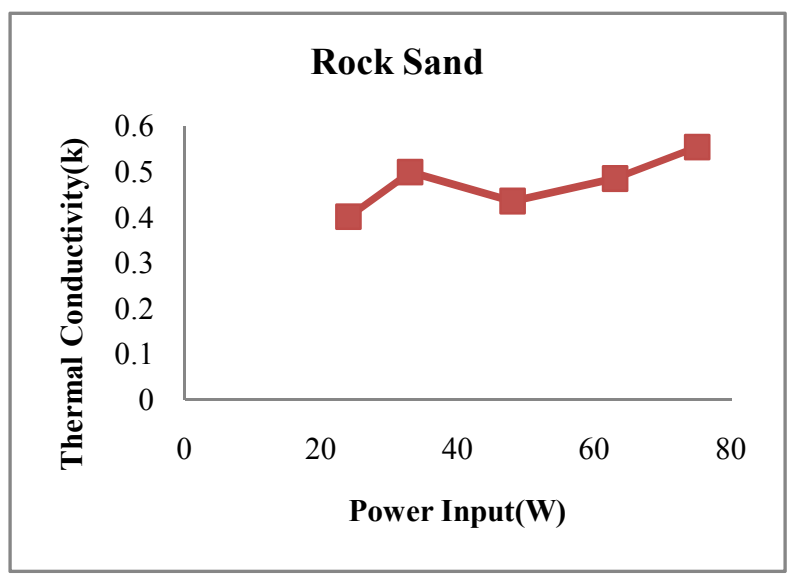

Fig 4 Variation of Thermal conductivity of Rock Sand powder with power input.

Fig. 4 it's represent the different thermal conductivity values of Rock sand at different q (Heat input) levels. Its shows that the thermal conductivity of Rock sand insulating powder is sharply increase and then it's linearly decrease simultaneously but whiling it's continuously heating up again the thermal conductivity is sharply increase.

Table 4 Thermal Conductivity of Brick Sand powder

\begin{tabular}{ccccccc}
\hline S.No. & $\mathbf{I}$ & $\mathbf{V}$ & $\mathbf{T i}$ & $\mathbf{T o}$ & $\mathbf{K}$ & $\mathbf{T M}$ \\
\hline 1 & 0.3 & 80 & 95.5 & 36.71 & 0.32 & 66 \\
2 & 0.33 & 100 & 117 & 40.66 & 0.34 & 79 \\
3 & 0.4 & 120 & 149.25 & 43.83 & 0.36 & 96 \\
4 & 0.45 & 140 & 168 & 53.16 & 0.44 & 111 \\
5 & 0.5 & 150 & 171 & 55.83 & 0.52 & 113 \\
\hline
\end{tabular}

Fig. 5 shows that the thermal conductivity of Brick sand insulating powder is varied linearly up to first starting levels of heat input (q), but it's continuous heating up and when it's across these starting levels the thermal conductivity is sharply increase

Fig. 6 show the different thermal conductivity levels of powder which is the combination of Brick Sand + POP powder. The thermal conductivity of powder is linearly increase and then got stable up to first levels of q, but after continuous increase in temperature there is a linear change of thermal conductivity. It is suitable for $100^{\circ} \mathrm{C}$ to $120^{\circ} \mathrm{C}$ because its thermal conductivity remain low as compared to other selected powder in this high temperature range.

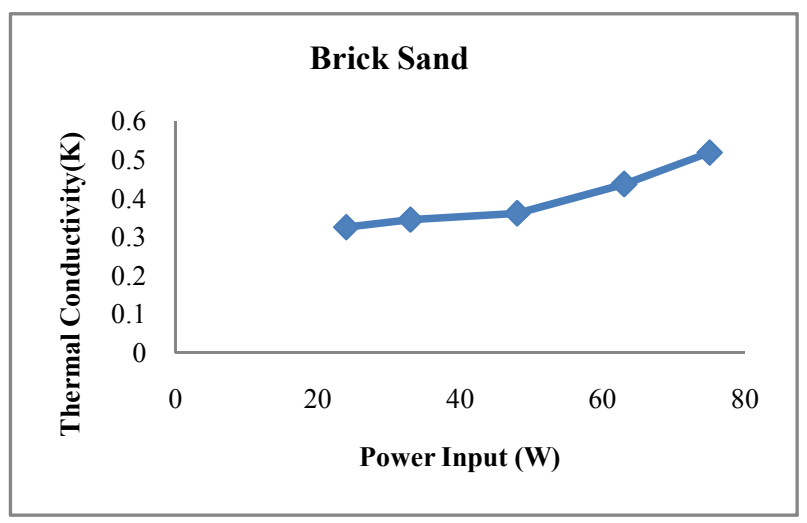

Fig. 5 Variation of Thermal Conductivity of Brick Sand powder with power input.

Table 5 Thermal conductivity of powder (Brick Sand + POP)

\begin{tabular}{ccccccc}
\hline S.No. & $\mathbf{I}$ & $\mathbf{V}$ & $\mathbf{T i}$ & $\mathbf{T o}$ & $\mathbf{K}$ & $\mathbf{T M}$ \\
\hline 1 & 0.3 & 80 & 83.25 & 18 & 0.29 & 51 \\
2 & 0.33 & 100 & 109.75 & 27 & 0.32 & 68 \\
3 & 0.4 & 120 & 160.5 & 38 & 0.31 & 99 \\
4 & 0.45 & 140 & 171.25 & 50.75 & 0.42 & 111 \\
5 & 0.5 & 150 & 175.75 & 51.83 & 0.48 & 114 \\
\hline
\end{tabular}

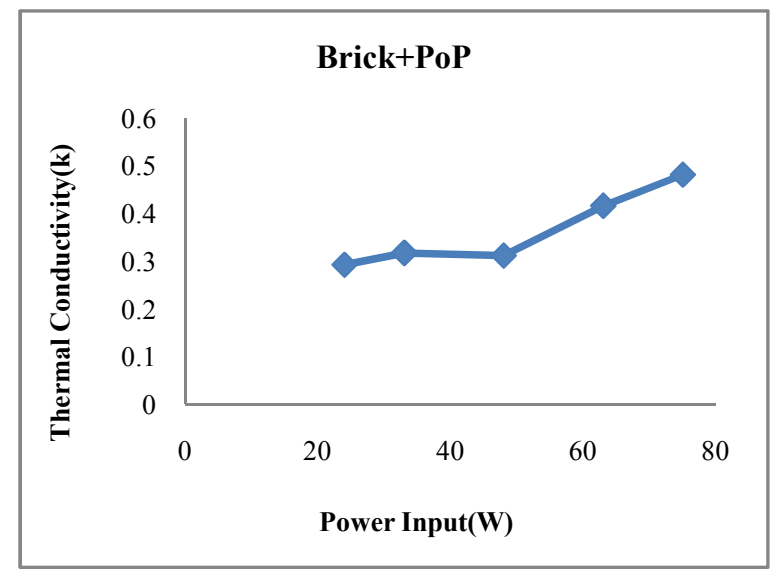

Fig. 6 Variation of Thermal Conductivity of powder (Brick Sand + POP) powder with power input

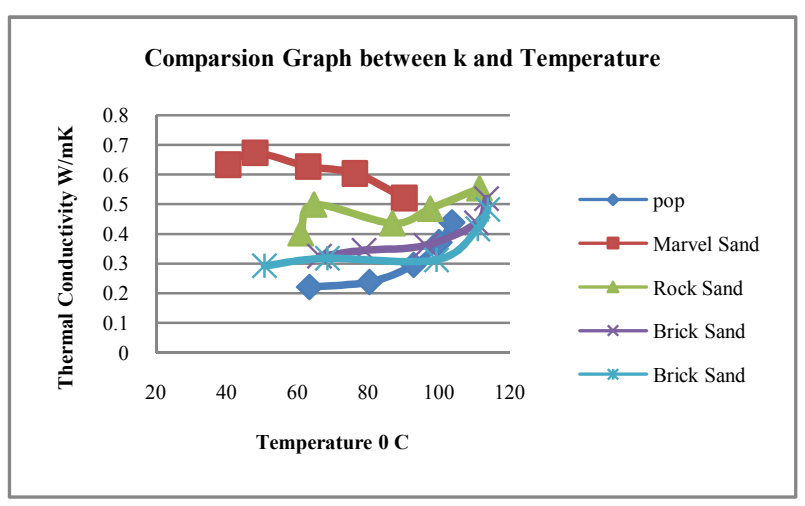

Fig. 7 Variation of Thermal Conductivity of powders with temperature.

\section{CONCLUSION}

This experimental work shows the variations in thermal conductivity of different selected insulating materials. This experimental work is also tell us that which types of material 
has to be prefer according to their low thermal conductivity value in different temperature ranges. This investigation has suggested that in the temperature range $\left(60^{\circ} \mathrm{C}\right.$ to $\left.80^{\circ} \mathrm{C}\right)$, the Plastic of Paris insulator material has low thermal conductivity value (lies between $0.21 \mathrm{~W} / \mathrm{mk}$ to $0.24 \mathrm{~W} / \mathrm{mk}$ ) which is very much low as compared to other selected insulating materials. In the next temperature range $\left(80^{\circ} \mathrm{C}-\right.$ $100^{\circ} \mathrm{C}$ ), again the thermal conductivity of Plastic of Paris is low $(0.295 \mathrm{~W} / \mathrm{mk})$, so instead of other selected insulating materials we has to use Plastic of Paris. So the Plastic of Paris is suitable for $0^{\circ} \mathrm{c}$ to $100^{\circ} \mathrm{c}$, because it has a low effective thermal conductivity property within this range. In the last selected temperature range $\left(100^{\circ} \mathrm{C}-120^{\circ} \mathrm{C}\right)$ the thermal conductivity level of powder (Brick Sand + POP powder) is $(0.41 \mathrm{~W} / \mathrm{mk}$ to $0.48 \mathrm{~W} / \mathrm{mk})$, for the same temperature range the other insulator's ( pop, brick sand, rock sand ) thermal conductivity values is high, in this high temperature range this powder give a low effective value of thermal conductivity. Heat input was varied to increase the temperature during investigation. In Indian market cost of pop powder, rock sand, marvel sand and brick sand is Rs.14, Rs.25, Rs.40 and Rs. 8 per $\mathrm{kg}$ respectively. So according to their low effective thermal conductivity value and less cost we can choose a more suitable insulating material.

\section{References}

1. Zheng $\mathrm{Q}$ and Chung D.D.L. Microporous calicium silicate thermal insulator. Material science and technology, 6:666_670, 1990.

2. B.Cecile, B.Marie-Elisabeth, V.Emeline and V. Gerard, Development of Eco-Friendly Porous Fired Clay Bricks Using Pore-Forming agents 143, (2014) 186-196

3. Industrial insulation group Fiberglass Insulation. Retrieved. November,10,2010,from http://composite. about.com/od/aboutglass/l/aa980630.htm , June 1998.

4. J. Fricke, High Temperatures, High Pressures 25, (1993) 379-390.
5. J. Kuhn, G. G“obel, S. Korder, M. Arduini-Schuster and J. Fricke, High Temperatures High Pressures 25, (1993) 343-351.

6. A Singh, M A Khan, J Gaur and G Gupta. 'Thermal Insulation of Energy Efficient Buildings'. Advances in Energy Research, AER -2006, p 410. [2]

7. Chi T.D, Bentz D.P, and Stutzman P.E. Microstructure and thermal conductivity of hydrated calcium silicate board materials. Journal of Building Physics, 31:55_67, 2007.

8. Industrial insulation group .Calcium Silicate Insulation. Retrieved. November, 10, 2010, from http:// www.amerisafe.net/uploads/msds/172387b9d2ce4f718 6d62e111dac696e.pdf, October 62003.

9. Carlslaw, H.S., Jaeger, J.C., Conduction of Heat in Solids,oxford University Press, 1959.

10. Healy, J.J., de Groot, J.J. and Kerstin, J., The Theory of the Transient Hot-wire Method for Measuring Thermal Conductivity, Physika 82C, 1968, 392-468

11. Griesinger, A., Spindler, K. und Hahne, E., Periodisches hitzdrahtverfamren zur Messung von Wärme- und Temperaturleitfähigkeit von geringen Stoffmengen, Heat and Mass Transfer, 32, 1997, 419425.

12. Božičević, J. Caharija, A. Influence of heat forcing function amplitude to dynamical measurement of thermal properties of liquids, Božičević Juraj ed., From sample to data and information, Croatian System Society 1993, 101-108.

13. B. V.Emeline and V. Gerard, Development of EcoFriendly Porous Fired Clay Bricks Using Pore-Forming agents 143, (2014) 186-196

\section{How to cite this article:}

Shubham Sharma and Shalab Sharma (2017) ' Some Studies On Investigating The Concept Of Determining Thermal Conductivity Of Various Insulating Powders Materials By Using Sphere In Sphere Method', International Journal of Current Advanced Research, 06(03), pp. 2836-2839.

DOI: http://dx.doi.org/10.24327/ijcar.2017.2839.0120 